\title{
Assistência de enfermagem à vítima de queimaduras: uma revisão da literatura
}

\author{
Nursing assistance to the victim of a burnt: a literature review
}

Asistencia de enfermería a la víctima quemada: revisión de la literatura

Yara dos Santos Sousa1*, Luana Araujo dos Santos ${ }^{1}$, Bianca Gonçalves de Andrade ${ }^{1}$, Andrey Hudson Interaminense Mendes de Araújo'.

\section{RESUMO}

Objetivo: Descrever e revisar sobre as ações do enfermeiro no cuidado ao paciente vítima de queimaduras. Métodos: Trata-se de uma revisão integrativa da literatura. A pesquisa dos artigos foi realizada nas bases de dados Scientific Eletronic Library Online (Scielo), Literatura Latino-americana e do Caribe em Ciências da Saúde (LILACS) e na Base de dados em enfermagem (BDENF). Os critérios de inclusão foram de artigos publicados entre 2016 e 2020, disponíveis na língua portuguesa, artigos originais e disponíveis na íntegra. Resultados: A análise dos artigos permitiu identificar as principais condutas do enfermeiro diante o paciente com queimaduras destacando as principais ações dele para o bom prognóstico desta vítima desde sua estabilização até a sua reabilitação. Considerações Finais: As queimaduras são traumas que acarretam grandes alterações na qualidade de vida das vítimas, diante disso, o enfermeiro e sua equipe devem ter ações padronizadas e efetivas que visem à estabilização, recuperação e reabilitação desse paciente incluindo a sua família no cuidado.

Palavras-chave: Cuidados de enfermagem, Unidades de queimados, Queimaduras.

\section{ABSTRACT}

Objective: Describe and review the nurse actions about the care with burn victims. Methods: This is about a integrative review from literature. The research was made based on Scientific Electronic Library Online (Scielo), Latin American and Caribbean Literature in Health Sciences (LILACS) and Nursing Databases (BDENF) databases. The inclusion criteria were from published articles between 2016 and 2020, available in Portuguese, original articles. Results: The article analysis allowed identify the main nurse conducts against burns patients, showing his main actions to a good victim prognosis since it stabilization until it rehabilitation. Final Considerations: Burns are traumas that result in big quality changes for victims life, that said, the nurse and his team must have standardized and effectives actions that aim the pacient rehabilitation, including his family in this care.

Key words: Nursing care, Burn units, Burns.

\section{RESUMEN}

Objetivo: Describir y revisar la actuación del enfermero en el cuidado de víctimas de quemaduras. Métodos: Se trata de una revisión integradora de la literatura. La búsqueda de artículos para los mismos realizada en la Biblioteca Científica Electrónica en Línea (Scielo), Literatura Latinoamericana y del Caribe en Ciencias de la Salud (LILACS) y en las bases de datos de la Base de Datos de Enfermería (BDENF). Los criterios de inclusión fueron artículos publicados entre 2016 y 2020, disponibles en portugués, artículos originales y disponibles en su totalidad. Resultados: El análisis de los artículos permite identificar las principales conductas de los enfermeros hacia los pacientes con quemaduras, destacando sus principales acciones para el buen pronóstico de esta víctima, desde la estabilización hasta la rehabilitación. Consideraciones finales: Las quemaduras son traumas que provocan cambios importantes en la calidad de vida de las víctimas, por lo que el enfermero y su equipo deben contar con acciones estandarizadas y efectivas encaminadas a estabilizar, recuperar y rehabilitar a este paciente a su cuidado.

Palabras clave: Cuidados de enfermería, Unidades de quemados, Quemaduras.

1 Universidade Paulista (UNIP), Brasília - DF. *E-mail: yarasousa96@gmail.com

SUBMETIDO EM: 5/2021

ACEITO EM: 6/2021

PUBLICADO EM: 7/2021 


\section{INTRODUÇÃO}

A queimadura se caracteriza por uma lesão traumática causada por acidentes por contato direto com agentes térmicos, químicos, radioativos, biológicos ou elétricos. As lesões por queimaduras podem ser classificadas, segundo a profundidade, como as de primeiro grau, que atingem somente a epiderme, causando basicamente dor, rubor e edema, não formando bolhas e evoluindo com descamações; nas de segundo grau, onde há lesão da epiderme e derme, com presença de bolhas, conhecidas como flictemas, e dor; e já nas de terceiro grau há o comprometimento das três camadas da pele, podendo chegar aos ossos, apresentando-se indolor devido à destruição de terminações nervosas (AIQUOC K, et al., 2019; CARVALHO RRS, et al., 2019).

As queimaduras são consideradas traumas graves ficando atrás somente de acidentes de trânsito, quedas e violência em geral. Inconsiderado um grave problema de saúde pública ocasionando grande número de casos e internações hospitalares. Estima-se que a cada ano 1 milhão de pessoas sofram algum tipo de acidente deste tipo. Desse total, 200 mil necessitam de assistência em pronto atendimento e 40 mil necessitam de internação para cuidados especializados. Os óbitos se dão em cerca de 2,5 mil casos de forma direta ou indireta. Estudos apontam que todas as faixas etárias são acometidas por esses acidentes, porém, a prevalência é maior em acidentes domésticos com crianças e acidentes laborais mais frequentes com o sexo masculino (AIQUOC K, et al., 2019; COSTA ACSM, et al., 2018; DUTRA JPS, et al., 2017; FILHO FMB, et al., 2019).

As complicações decorrentes desse tipo de trauma variam de problemas psicológicos até danos nos sistemas, cardiovascular, respiratório, imunológico e renal, além de choques, se destacando o hipovolêmico e séptico. Infecções seguidas de choque séptico constituem a maior causa de mortalidade nesses pacientes. Estes agravos necessitam de uma complexa assistência multidisciplinar, o que antes ficava restrito apenas ao médico cirurgião geral agora devido a sua gravidade e complexidade exige um atendimento englobando áreas médica e não-médicas (GUANILO MEE, et al., 2016; HERIQUE DM, et al., 2017).

As vítimas de queimaduras têm importantes impactos emocionais devido à dor e sequelas físicas e funcionais, o que interfere em sua recuperação. Os profissionais que acompanham este paciente representam um importante ponto de apoio, na realização de cuidados físicos e apoio emocional. Nesse sentido, as ações de enfermagem não devem se restringir apenas a executar técnicas corretas ou prescrições, mas principalmente a ajudar o paciente e sua a família a compreenderem o tratamento e ter uma melhor aceitação das alterações e sequelas que possuem e que poderão vir a ter devido a este trauma (LANÇONI JÚNIOR AC, et al., 2017; LIMA VX, et al., 2018).

Tais pacientes relatam uma grande mudança na sua qualidade de vida após esses acidentes, dentre as principais implicações estão mudanças na sua vida social, laboral, familiar, além do grande prejuízo psicológico devido às alterações na autoimagem o que, muitas vezes, é a causa do atraso ao retorno às atividades do cotidiano. Destacam-se, também, o tempo gasto com a realização de cuidados com as queimaduras, além de limitações físicas e persistência de dor (MALTA DC, et al., 2020; MESCHIAL WC, et al., 2020).

No atendimento primário a essa vítima deve ser priorizada uma boa e eficaz avaliação clínica do enfermeiro, principalmente no que diz respeito à avaliação da lesão quanto ao grau, a Superfície Corporal Queimada (SCQ), presença de lesão de vias aéreas, necessidades psicobiologias, como oxigenação, hidratação, integridade cutaneomucosa, eliminações, regulação (térmica, vascular, hidroeletrolítica), e percepção dolorosa. $O$ tratamento deve estar focado primariamente na hidratação e prevenção de infecções (MOLA R, et al., 2018; MORAES LP, et al., 2016).

Diante da complexidade e peculiaridades no atendimento ao adulto vítima de queimaduras no que diz respeito ao seu manejo clínico para um melhor prognóstico e diminuição da mortalidade e do grande número de casos com esse tipo de acidente, uma abordagem inicial metódica e bem estruturada com ações de reanimação e estabilização em tempo hábil são primordiais. Portanto, faz-se necessário que o enfermeiro, bem como sua equipe, seja capacitado para planejar e implementar ações efetivas para uma melhor 
assistência imediata e a longo prazo dessa condição, visando ações que podem melhorar o prognóstico e a qualidade de vida desse paciente (MOULIN LL, et al., 2018; MOURA NR, et al., 2019).

Diante o disposto, o objetivo desse estudo é, por meio da literatura recente, destacar as principais ações do enfermeiro e sua equipe frente ao paciente vítima de queimaduras, desde o atendimento inicial, até a sua recuperação e reabilitação, além de destacar a importância desses profissionais diante desse agravo.

\section{MÉTODOS}

Trata-se de uma revisão integrativa da literatura por meio das bases de dados Scientific Eletronic Library Online (SciELO), Literatura Latino-americana e do Caribe em Ciências da Saúde (LILACS) e na Bases de dados em enfermagem (BDENF), no período de janeiro a abril de 2021. Foram utilizados na busca dos trabalhos científicos os seguintes descritores contidos no DeCS, seguidos do operador booleano "and": cuidados de enfermagem and queimaduras and unidades de queimados.

Usaram-se como critérios de inclusão, previamente estabelecidos na estratégia de busca dos artigos: artigos publicados entre 2016 e 2020, disponíveis na língua portuguesa, artigos originais e disponíveis na íntegra. Para a exclusão de artigos foram aplicados os seguintes critérios: materiais publicados anterior a 2016, artigos em outros idiomas e temas que fugiam da proposta escolhida. Dessa forma, facilitou-se, então, a avaliação e análise das informações, ofertando aspectos que contribuíssem com o objetivo desse estudo. A Figura 1 demonstra o processo de seleção dos artigos com a utilização dos critérios de inclusão e exclusão.

Figura 1 - Fluxograma do processo de seleção dos artigos que compõem a amostra.

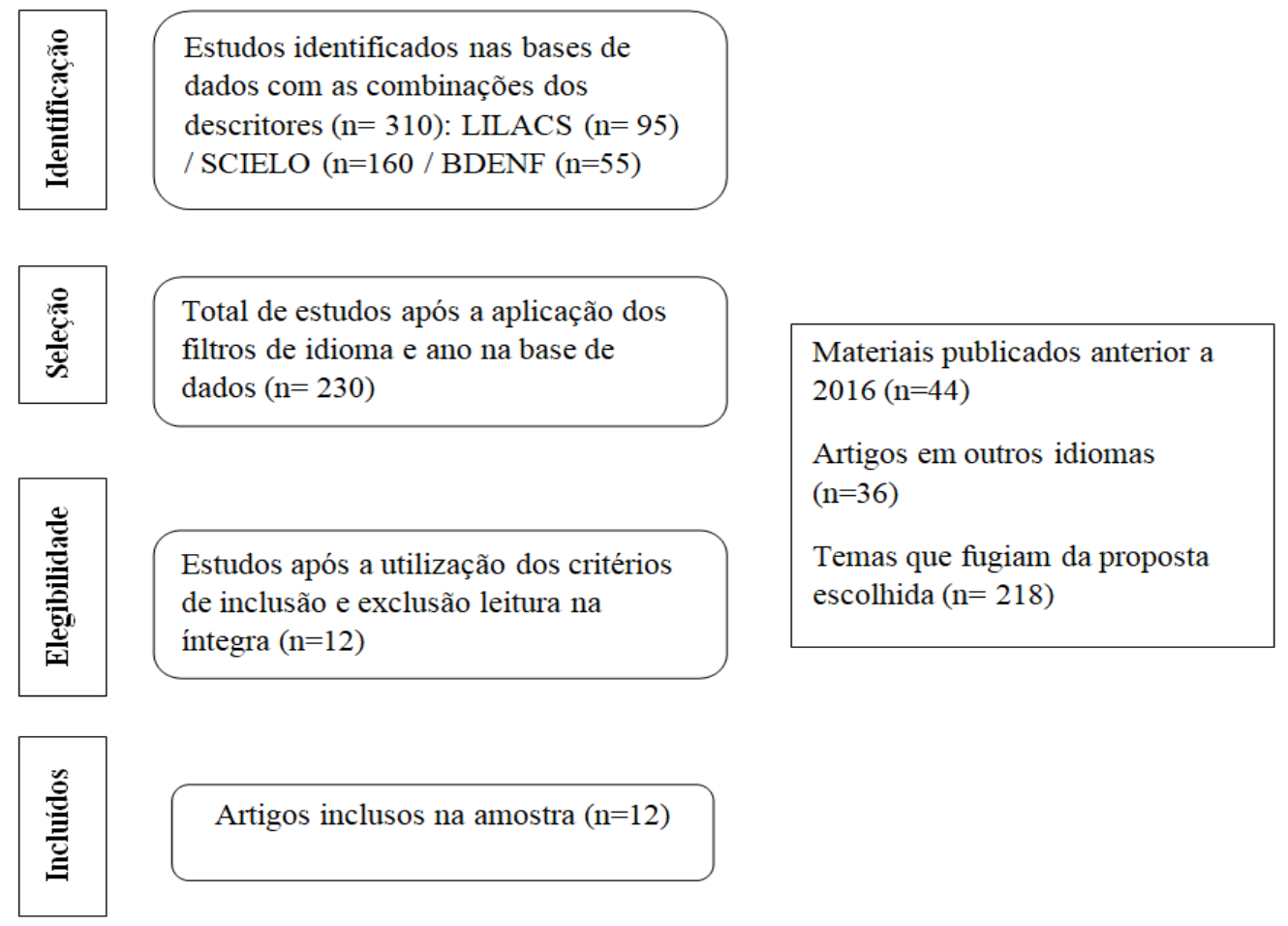

Fonte: Sousa YS, et al., 2021.

$\mathrm{Na}$ busca dos trabalhos, com os descritores citados acima, foram encontrados 230 artigos, sendo estes 52 da SciELO, 111 da LILACS e 67 da BDENF. Após a leitura do título, resumo e aplicado os critérios de exclusão, foram incluídos 12 trabalhos nesta revisão da literatura.

\section{RESULTADOS}

Foram expostas informações do conteúdo dos 12 artigos contidos na discussão desta revisão de literatura, na ordem decrescente ao ano de publicação. Foram interpretados e sintetizados todos os resultados através da análise e comparação dos dados contidos nesses artigos, que estão descritos no Quadro 1. 
Quadro 1 - Distribuição dos artigos de acordo com o título, autores, objetivo, método, conclusão e ano de publicação, 2021.

\begin{tabular}{|c|c|c|c|c|c|}
\hline $\mathbf{N}^{\circ}$ & Título & Autores, Ano & Objetivo & Método & Conclusão \\
\hline 응 & $\begin{array}{l}\text { A dor da queimadura e suas } \\
\text { singularidades: } \\
\begin{array}{ll}\text { de } & \text { enferepções } \\
\text { assistenciais. } & \end{array}\end{array}$ & $\begin{array}{l}\text { Carvalho RRS, et } \\
\text { al., } 2019\end{array}$ & $\begin{array}{l}\text { Analisar as percepções de } \\
\text { enfermeiras assistenciais acerca } \\
\text { da dor associada à queimadura. }\end{array}$ & $\begin{array}{l}\text { Realização de entrevistas } \\
\text { semiestruturadas com oito } \\
\text { enfermeiras assistenciais de } \\
\text { um centro de tratamento de } \\
\text { queimados. }\end{array}$ & $\begin{array}{l}\text { Faz-se necessário investimento } \\
\text { na formação da equipe de } \\
\text { enfermagem para uma melhor } \\
\text { assistência qualificada e } \\
\text { humanizada. }\end{array}$ \\
\hline $\begin{array}{l}N \\
\text { 은 } \\
\frac{1}{4}\end{array}$ & $\begin{array}{l}\text { Características e } \\
\text { complicações associadas às } \\
\text { queimaduras de pacientes } \\
\text { em unidade de queimados. }\end{array}$ & Mola R, et al., 2018 & $\begin{array}{l}\text { Identificar as características e } \\
\text { complicações associadas às } \\
\text { queimaduras de pacientes } \\
\text { internados em unidade de } \\
\text { queimados. }\end{array}$ & $\begin{array}{l}\text { Estudo descritivo, analítico, } \\
\text { quantitativo e documental de } \\
87 \text { prontuários. }\end{array}$ & $\begin{array}{l}\text { Há uma necessidade de } \\
\text { atuação multiprofissional } \\
\text { preventiva para tratar } \\
\text { principalmente queimaduras } \\
\text { classificadas como graves. }\end{array}$ \\
\hline $\begin{array}{l}m \\
\text { 은 } \\
\frac{1}{4}\end{array}$ & 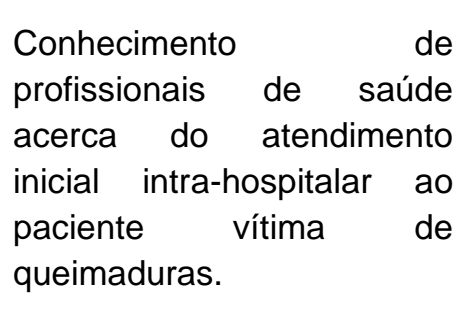 & Pan R, et al., 2018 & $\begin{array}{l}\text { Descrever o conhecimento de } \\
\text { profissionais de saúde acerca do } \\
\text { atendimento inicial intra-hospitalar } \\
\text { ao paciente vítima de queimadura. }\end{array}$ & $\begin{array}{l}\text { Estudo descritivo de } \\
\text { abordagem qualitativa, foi } \\
\text { realizado em } 3 \text { unidades de } \\
\text { urgência e emergência com } \\
\text { coletas de dados e entrevistas } \\
\text { semiestruturadas. }\end{array}$ & $\begin{array}{l}\text { É necessária mais capacitação } \\
\text { aos profissionais acerca das } \\
\text { queimaduras, pois eles } \\
\text { apresentaram conhecimento } \\
\text { básico sobre o assunto mesmo } \\
\text { possuindo } \\
\text { profissional. }\end{array}$ \\
\hline 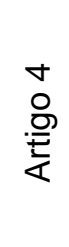 & $\begin{array}{l}\text { Indicadores clínicos da } \\
\text { sepse no paciente } \\
\text { queimado. }\end{array}$ & $\begin{array}{l}\text { Rança CSF, et al., } \\
2018\end{array}$ & $\begin{array}{l}\text { Identificar a prevalência de sepse } \\
\text { e caracterizar os pacientes } \\
\text { queimados em um centro de } \\
\text { tratamento de queimados. }\end{array}$ & $\begin{array}{l}\text { Estudo transversal, } \\
\text { quantitativo, retrospectivo, com } \\
\text { técnica de coleta de dados por } \\
\text { análise de prontuários dos } \\
\text { pacientes. }\end{array}$ & $\begin{array}{l}\text { Com a taxa elevada da } \\
\text { prevalência de sepse, faz-se } \\
\text { necessário definir indicadores } \\
\text { clínicos e planejamento de } \\
\text { cuidados otimizados e seguros. }\end{array}$ \\
\hline
\end{tabular}




\begin{tabular}{|c|c|c|c|c|c|}
\hline $\mathbf{N}^{\circ}$ & Título & Autores, Ano & Objetivo & Método & Conclusão \\
\hline $\begin{array}{l}10 \\
\text { 은 } \\
\frac{\ln }{4}\end{array}$ & $\begin{array}{l}\text { Perfil funcional segundo a } \\
\text { Classificação Internacional } \\
\text { de Funcionalidade, } \\
\text { Incapacidade e saúde em } \\
\text { pacientes queimados } \\
\text { atendidos em hospital } \\
\text { público. }\end{array}$ & $\begin{array}{l}\text { Costa ACSM, et al., } \\
2018\end{array}$ & $\begin{array}{l}\text { Definir o perfil funcional de } \\
\text { pacientes queimados atendidos } \\
\text { em hospital público de acordo com } \\
\text { a Classificação Internacional de } \\
\text { Funcionalidade, Incapacidade e } \\
\text { Saúde (CIF). }\end{array}$ & $\begin{array}{l}\text { Estudo transversal, } \\
\text { observacional de campo, com } \\
\text { abordagem qualitativo- } \\
\text { quantitativo. Coleta de dados } \\
\text { realizada em uma unidade de } \\
\text { tratamento de queimados. }\end{array}$ & $\begin{array}{l}\text { E necessário o uso da CIF para } \\
\text { classificar a mobilidade e a } \\
\text { estrutura envolvida como } \\
\text { atividades e funcionalidades do } \\
\text { paciente para reconhecer } \\
\text { fatores que podem interferir a } \\
\text { reabilitação. }\end{array}$ \\
\hline$\stackrel{0}{\circ}$ & $\begin{array}{l}\text { Fluxos assistenciais de } \\
\text { médios e grandes } \\
\text { queimados nas regiões e } \\
\text { redes de atenção à saúde de } \\
\text { Minas Gerais. }\end{array}$ & $\begin{array}{l}\text { Souza MT, et al., } \\
2018\end{array}$ & $\begin{array}{l}\text { A configuração das redes } \\
\text { assistenciais tem efeitos no } \\
\text { processo saúde-doença das } \\
\text { populações, organizando o fluxo } \\
\text { de pacientes na busca por } \\
\text { cuidado, especialmente no SUS, } \\
\text { reforçando a lógica de redes } \\
\text { regionalizadas e hierarquizadas } \\
\text { de atenção. }\end{array}$ & $\begin{array}{l}\text { Este artigo mapeou o fluxo dos } \\
\text { pacientes com queimaduras } \\
\text { graves no âmbito do SUS, no } \\
\text { Estado de Minas Gerais no } \\
\text { período de janeiro de } 2013 \text { a } \\
\text { dezembro de } 2015 \text {. }\end{array}$ & $\begin{array}{l}\text { Com o estudo é possível } \\
\text { identificar que há necessidade } \\
\text { de investimentos para a criação } \\
\text { de centros de referência com } \\
\text { distribuição equânime no Estado } \\
\text { de Minas Gerais. }\end{array}$ \\
\hline 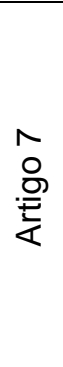 & $\begin{array}{l}\text { Aprazamento seguro da } \\
\text { terapia analgésica com } \\
\text { opioides no paciente } \\
\text { queimado: um estudo } \\
\text { transversal. }\end{array}$ & $\begin{array}{l}\text { Henrique DM, et al., } \\
2017\end{array}$ & $\begin{array}{l}\text { Descrever a terapêutica dos } \\
\text { opioides na analgesia de } \\
\text { pacientes queimados e identificar } \\
\text { interações medicamentosas no } \\
\text { processo de aprazamento, } \\
\text { contribuindo na prevenção da } \\
\text { depressão respiratória. }\end{array}$ & $\begin{array}{l}\text { Análise de } 272 \text { prontuários de } \\
\text { pacientes queimados com } \\
\text { episódios de depressão } \\
\text { respiratórias com o uso de } \\
\text { naloxone com pressão arterial } \\
\text { menor de } 110 / 60 \mathrm{mmHg} \text {. } \\
\text { Estudo retrospectivo. }\end{array}$ & $\begin{array}{l}\text { O enfermeiro deve estar atento } \\
\text { com o aprazamento indevido de } \\
\text { opioides, pois pode ocasionar } \\
\text { interação medicamentosa } \\
\text { potencializando seu efeito } \\
\text { farmacológico levando queda do } \\
\text { nível de consciência e outras } \\
\text { complicações. }\end{array}$ \\
\hline 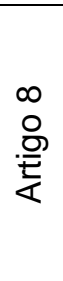 & $\begin{array}{l}\text { Perfil Epidemiológico dos } \\
\text { pacientes com lesão } \\
\text { inalatória que foram } \\
\text { atendidos em uma Unidade } \\
\text { de Queimados de um } \\
\text { Hospital de Pronto-Socorro. }\end{array}$ & $\begin{array}{l}\text { Silveira RC, et al., } \\
2017\end{array}$ & $\begin{array}{l}\text { Descrever o perfil e desfecho pós- } \\
\text { alta hospitalar, além de sequelas } \\
\text { pulmonares em pacientes com } \\
\text { queimaduras inalatórias } \\
\text { internados no Hospital de Pronto } \\
\text { Socorro de Porto Alegre. }\end{array}$ & $\begin{array}{l}\text { Estudo quantitativo, descritivo } \\
\text { e transversal com coleta de } \\
\text { dados no Hospital de Pronto } \\
\text { Socorro de Porto Alegre. }\end{array}$ & $\begin{array}{l}\text { Inserção de fisioterapeutas nos } \\
\text { diversos níveis de atenção ao } \\
\text { cuidado do paciente queimado. }\end{array}$ \\
\hline
\end{tabular}




\begin{tabular}{|c|c|c|c|c|c|}
\hline $\mathbf{N}^{\circ}$ & Título & Autores, Ano & Objetivo & Método & Conclusão \\
\hline $\begin{array}{l}0 \\
\text { 은 } \\
\frac{1}{2}\end{array}$ & $\begin{array}{l}\text { Percepção da equipe de } \\
\text { enfermagem acerca da } \\
\text { prática da educação em } \\
\text { saúde em um centro de } \\
\text { tratamento de queimados. }\end{array}$ & $\begin{array}{l}\text { Lima VX, et al., } \\
2016\end{array}$ & $\begin{array}{l}\text { Analisar a percepção da equipe de } \\
\text { enfermagem acerca da prática de } \\
\text { educação em saúde no contexto } \\
\text { hospitalar. }\end{array}$ & $\begin{array}{l}\text { Estudo qualitativa, descritiva e } \\
\text { exploratória com participação } \\
\text { de } 8 \text { enfermeiras. Coleta } \\
\text { realizada por meio de } \\
\text { entrevista semiestruturada. }\end{array}$ & $\begin{array}{l}\text { Necessidade de planejar ações } \\
\text { educativas para serem } \\
\text { desenvolvidas junto aos } \\
\text { pacientes e/ou familiares. }\end{array}$ \\
\hline$\frac{\circ}{\circ}$ & $\begin{array}{l}\text { Guideline das ações no } \\
\text { cuidado de enfermagem ao } \\
\text { paciente adulto queimado. }\end{array}$ & $\begin{array}{l}\text { Pinho FM, et al., } \\
2016\end{array}$ & $\begin{array}{l}\text { Elaborar um guideline para o } \\
\text { cuidado de enfermagem ao } \\
\text { paciente adulto queimado a partir } \\
\text { de ações de enfermagem } \\
\text { identificadas pelos enfermeiros. }\end{array}$ & $\begin{array}{l}\text { Estudo qualitativo, método de } \\
\text { pesquisar convergente } \\
\text { assistencial. }\end{array}$ & $\begin{array}{l}\text { Foi constituída uma ferramenta } \\
\text { para a prática do cuidado de } \\
\text { enfermagem ao paciente adulto } \\
\text { queimado. }\end{array}$ \\
\hline 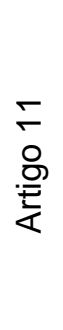 & $\begin{array}{l}\text { Avaliação da qualidade de } \\
\text { vida relacionada à saúde no } \\
\text { primeiro ano após a } \\
\text { queimadura. }\end{array}$ & $\begin{array}{l}\text { Guanilo MEE, et al., } \\
2016\end{array}$ & $\begin{array}{l}\text { Comparar a percepção de } \\
\text { qualidade de vida de vítimas de } \\
\text { queimaduras entre o } 4^{\circ} \text { e } 6^{\circ} \text { mês e } \\
\text { entre o } 9^{\circ} \text { e } 12^{\circ} \text { mês após a alta } \\
\text { hospitalar, de acordo com o sexo, } \\
\text { superfície corporal queimada e } \\
\text { visibilidade das cicatrizes. }\end{array}$ & $\begin{array}{l}\text { Estudo longitudinal, aplicando } \\
\text { formulários de dados } \\
\text { sociodemográficos e o medical } \\
\text { outcomesStudy36-Item Short- } \\
\text { FormSurvey. }\end{array}$ & $\begin{array}{l}\text { Foi observada piora de } \\
\text { qualidade de vida na fase } \\
\text { precoce e melhora na fase } \\
\text { tardia, principalmente nos } \\
\text { aspectos físicos e emocionais } \\
\text { entre os homens. }\end{array}$ \\
\hline 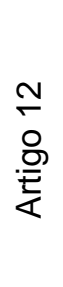 & $\begin{array}{l}\text { Apoio social e qualidade de } \\
\text { vida na perspectiva de } \\
\text { pessoas que sofreram } \\
\text { queimaduras. }\end{array}$ & $\begin{array}{l}\text { Moares LP, et al., } \\
2016\end{array}$ & $\begin{array}{l}\text { Conhecer a partir da perspectiva } \\
\text { do paciente, o apoio social e } \\
\text { fatores que interferem na } \\
\text { qualidade de vida durante a } \\
\text { recuperação após queimadura. }\end{array}$ & $\begin{array}{l}\text { Estudo qualitativo do tipo } \\
\text { descritivo exploratório, com } \\
\text { participação de paciente } \\
\text { adultos internados em um } \\
\text { centro de referência a } \\
\text { queimados. }\end{array}$ & $\begin{array}{l}\text { A recuperação pós queimadura } \\
\text { é marcada pela dificuldade de } \\
\text { adaptações às mudanças com } \\
\text { isto e importante ter o apoio } \\
\text { social para diminuir o sofrimento } \\
\text { e melhorar a recuperação. }\end{array}$ \\
\hline
\end{tabular}

Fonte: Sousa YS, et al., 2021.

REAEnf | Vol. 12 | DOI: https://doi.org/10.25248/REAEnf.e7770.2021_ Página $\mathbf{6}$ de $\mathbf{1 0}$




\section{DISCUSSÃO}

Após análise descritiva dos artigos demonstrados no Quadro 1, optou-se pela definição de três categorias para a discussão dos resultados, tendo em vista que há informações nestas publicações que podem ser trabalhadas simultaneamente. As categorias definidas foram: Cuidados primários realizados pela equipe de enfermagem; Cuidados de enfermagem secundários ao paciente queimado; Recuperação e reabilitação pósqueimaduras.

\section{Cuidados primários realizados pela equipe de enfermagem}

O primeiro atendimento é decisivo no prognóstico desse paciente, pois evita o agravamento das queimaduras, bem como futuras sequelas decorrentes delas. Em um estudo publicado em 2018 ficou apontado que os profissionais que realizam esse primeiro atendimento não apresentaram conhecimentos satisfatórios em relação às condutas iniciais. Diante disso, um estudo publicado em 2016 evidencia a importância e necessidade de uma padronização da assistência de enfermagem nesses casos, bem como uma unidade especializada para o tratamento desse paciente (MOLA R, et al., 2018; PAN R, et al., 2018).

Em publicações recentes acerca das condutas iniciais nesse tipo de trauma, fica evidente a importância de ações como avaliação de vias aéreas e respiração, avaliação da lesão, exposição da área queimada, presença de queimaduras circulares no tórax, punção de acesso venoso, periférico se possível, analgesia, e verificação da imunização antitetânica, observando a necessidade de realizar essa vacina com urgência se não comprovada (PAN R, et al., 2018).

No que diz ao aspecto respiratório desse paciente, ele pode apresentar dispneia por queimaduras nas vias aéreas ou lesão por inalação. Um estudo realizado em 2018 aponta que 55 a 80\% dos óbitos decorrentes de incêndio se dão por inalação de fumaça, que é uma das causas mais comuns de insuficiência respiratória em queimados. Os principais sinais e sintomas de lesões inalatórias são a dispneia, fuligem no escarro, lacrimejamento, estridores, sibilâncias e tosse produtiva. Destacam-se como principais condutas de enfermagem: verificação e controle da respiração, saturação de oxigênio, avaliação de extremidades, oxigenoterapia quando necessário, bem como cuidados pós intubação quando esta for realizada (MOLA R, et al., 2018; PESSOA LMB, et al., 2018).

A classificação da extensão da queimadura no adulto se dá da seguinte forma: se atribui a cada seguimento corporal o valor nove ou o dobro dele, que é conhecida como "Regra dos Nove $+1 \%$ ". Dessa forma, temos a cabeça como valor $9 \%$, tronco anterior $18 \%$, tronco posterior $18 \%$, membros superiores $9 \%$ cada, membros inferiores $18 \%$ cada, genitais $1 \%$. Para áreas pequenas ou que atinjam apenas partes dos seguimentos do corpo utiliza-se o tamanho da palma da mão do paciente incluindo os dedos o que equivale a $1 \%$. Nas crianças a cabeça equivale a $21 \%$ e membros inferiores $12 \%$, já nos demais seguimentos não diferem do adulto (PAN R, et al., 2018).

A gravidade do paciente se determina da seguinte forma: Pequenos Queimados, $1^{\circ}$ e $2^{\circ}$ grau com até $10 \%$ da SCQ; Médios Queimados, 1ํ e 20 grau entre 10\% e 25\% da SCQ e 30 grau até $10 \%$ da SCQ queimadura de face, mãos ou pés; e, por fim, Grande Queimado, $1^{\circ}$ e $2^{\circ}$ grau entre $26 \%$ da SCQ e $3^{\circ}$ grau acima de $10 \%$ da SCQ (MOLA R, et al., 2018).

A hidratação venosa é essencial, pois o choque hipovolêmico é uma das principais complicações, com prevalência maior em grandes queimados. Dessa forma, faz-se necessária a punção de dois acessos venosos periféricos, preferencialmente em pele íntegra. $\mathrm{Na}$ impossibilidade, realizar acesso em área atingida (em queimaduras de $1^{\circ}$ grau), realizar a fixação com sutura. Para o grande queimado, preconiza-se um acesso profundo e um periférico, este primeiro será utilizado para infusão de drogas vasoativas e mensuração de pressão venosa central (PVC), o segundo para hidratação (MOLA R, et al., 2018).

Para o cálculo correto da hidratação utiliza-se a fórmula de PARKLAND que será baseada no peso e SCQ (2-4 $\mathrm{ml}$ X SCQ\% X Kg), 50\% do volume calculado nas primeiras 8 horas e $50 \%$ nas 16 horas seguintes. As soluções recomendadas para a hidratação são cristaloides como, por exemplo, o Ringer Lactato (PAN R, et al., 2018). 
Quanto a dor, queimaduras de $1^{\circ}$ e $2^{\circ}$ graus tem menos destruição de terminações nervosas, ocasionado assim mais dor que as de $3^{\circ}$ grau. No entanto se observa que as queimaduras de $3^{\circ}$ grau no processo de cicatrização causam dor ao paciente devido às terminações ficarem expostas aos estímulos externos. Nesse contexto o enfermeiro tem papel importante na avaliação e manejo da dor deste paciente (PINHO FM, et al., 2016).

Os opioides são analgésicos potentes comumente usados em pacientes com dor moderada a alta. Para a obtenção de uma analgesia eficaz e potencializada, geralmente, é usada a combinação de medicamentos, o que diminui doses individuais e efeitos indesejáveis. Porém, apesar de ser uma prática muita utilizada é de suma importância que o enfermeiro conheça a farmacodinâmica e farmacocinética dessas drogas para se evitar afeitos adversos com o uso de opioides (LIMA VX, et al., 2018). Nesse contexto a equipe de enfermagem deve estar atenta a barreiras de segurança na administração desses medicamentos, monitorização, e reconhecimento de alterações que indiquem depressão respiratória (RANÇÃO CSF, et al., 2018)

Nas feridas além da avaliação o enfermeiro deve prescrever o curativo correto de acordo com as características das lesões. Os primeiros cuidados a serem adotados serão: lavagem imediata da área atingida com água clorada ou soro fisiológico $0,9 \%$, próximo da temperatura corpórea, devido à termorregulação, ou com solução de clorexidina a $4 \%$. Após isso, a cobertura de primeira escolha deve ser a sulfadiazina de prata $1 \%$, bem como realizar a oclusão com compressa cirúrgica atadura de crepom. Nas queimaduras em face, devem ser utilizados ácidos graxos essenciais para $1^{\circ}$ grau e colagenase creme nas queimaduras de $2^{\circ}$ ou $3^{\circ}$ graus (MOLA R, et al., 2018; MOULIN LL, et al., 2018; PAN R, et al., 2018).

\section{Cuidados de enfermagem secundários ao paciente queimado}

Com a estabilização inicial da vítima de queimaduras é primordial a prevenção de complicações e sequelas. Fatores relacionados ao paciente como idade, estado imunológico e nutricional, contribuem diretamente para o prognóstico deste. Fatores como agente etiológico, características, grau e a extensão da lesão também são fatores associados à evolução positiva ou negativa desse paciente. Um estudo realizado em 2018 evidenciou que queimaduras com extensões iguais a 30\% apresentaram 2,57 mais chances de apresentarem complicações associadas (MOULIN LL, et al., 2018).

Destacam-se como principais complicações: dor na região, disfunções, e processos infecciosos das feridas seguidos de sepse. Um estudo publicado em 2018 demonstra que atualmente a sepse é a maior causa de mortalidade em unidades de terapia intensiva, sendo também a complicação mais frequente em pacientes com queimaduras, e responsável pela maior parte dos óbitos nesses casos (MOULIN LL, et al., 2018; ROCHA JLFN, et al., 2016).

Desta forma o enfermeiro além de gerenciar as etapas da assistência prestada a esse paciente também realiza intervenções voltadas a esse público, portanto, deve possuir conhecimento teórico e prático para que esteja atento as principais complicações decorrentes das queimaduras. Tendo em vista a importância da constante avaliação e condutas que minimizem ou excluam o risco destas para a prevenção da morbidade e mortalidade decorrentes dessa condição (ROCHA JLFN, et al., 2016).

Necroses, proteínas degradadas, e diminuição do oxigênio nas áreas afetadas, contribuem para o desenvolvimento de infecções. Nesse contexto, é importante que o enfermeiro faça uma avaliação eficaz dessas feridas para o correto manejo e prevenção de sepse. O reconhecimento dos critérios clínicos para essa condição é primordial para o reconhecimento e tratamento precoces desta condição (ROCHA JLFN, et al., 2016).

$\mathrm{Na}$ assistência ao paciente queimado, após a fase estabilização, o enfermeiro deve principalmente observar alterações que possam indicar a sepse como: alterações na temperatura $>38.3^{\circ} \mathrm{C}$ ou $<36^{\circ} \mathrm{C}$, frequência cardíaca acima de 90 batimentos por minuto, frequência respiratória acima de 20 incursões por minuto, e hipotensão. Além de acompanhamento de exames laboratoriais como leucograma (ROCHA JLFN, et al., 2016). 
Os curativos também são importantes intervenções realizadas pelo enfermeiro no acompanhamento da vítima de queimaduras. Nas lesões recentes, os curativos com prata são os mais indicados, pois permitem um uso em longo prazo e previnem infecções. É preconizada a troca a cada 12 horas no caso exsudação em excesso e a cada 24 horas em feridas com baixo exsudado ou conforme especificação do produto. No final do tratamento é mais prevalente o uso de ácidos graxos essenciais em tecidos de granulação, pois favorece a angiogênese e epitelização. Há ainda feridas que necessitam de desbridamento químico ou mecânico quando apresentam tecidos desvitalizados (MOLA R, et al., 2018).

\section{Recuperação e reabilitação pós-queimaduras}

Alterações físicas, sistêmicas, funcionais, laborais e emocionais, são algumas das repercussões na vida de pacientes vítimas de queimaduras, essas interferem tanto na qualidade de vida quanto nos seus relacionamentos sociais. A presença de cicatrizes, continuidade de rotina de curativos e impedimento de exposição ao sol são fatores descritos como causadores de vergonha, medo e ansiedade em pacientes vítimas de queimaduras segundo um estudo realizado em 2016. Desta forma, é de extrema importância a atuação multidisciplinar e integral na reabilitação do paciente, não visando apenas às alterações físicas (RODRIGUES LA, et al., 2019; SILVA JAC, et al., 2018).

A vítima de queimaduras apresenta alterações como comprometimento de articulações de força de alguns ou diversos músculos em diversas partes do corpo. Essas alterações repercutem muitas vezes em tarefas diárias simples. Além de alterações da imagem o que trazem consequências psicológicas negativas a longo prazo. Um estudo de 2016 aponta que principalmente após os primeiros 6 meses após a alta hospitalar os aspectos físicos e emocionais apresentam maior fragilidades e comprometimento (RODRIGUES LA, et al., 2019; SILVEIRA RC, et al., 2017).

O período pós-hospitalização pode trazer ao paciente o sentimento de fragilidade devido a essa sua nova condição atreladas à distância familiares a rotina intensa de cuidados pelo qual nunca passou. Dessa forma um estudo de 2016 destaca que equipe de enfermagem deve atuar nesse contexto restabelecendo tanto funções físicas quanto favorecendo uma rede de apoio social a este paciente sempre tendo uma assistência que leve em consideração as necessidades individuais. A participação de familiares pode ajudar no cuidado e na construção de uma melhor organização da assistência prestada, contribuindo para a evolução do estado de saúde do paciente (RODRIGUES LA, et al., 2019; SOUZA MT, et al., 2018).

Um estudo de 2016 evidencia que as atividades educativas promovidas pela equipe de enfermagem devem começar desde a hospitalização, estas devem promover o autocuidado, bem como explicar de forma clara e objetiva os tratamentos e procedimentos a serem realizados. A criação de espaços de discussão nas unidades de tratamento são estratégias utilizadas para que tanto os pacientes como os familiares tirem suas dúvidas (SILVEIRA RC, et al., 2017).

Dessa forma fica evidente na literatura que os pacientes que sofrem esse trauma necessitam de uma rede organizada e especializada para o seu tratamento, e recuperação adequados. A fase de recuperação e reabilitação das vítimas de queimaduras é complexa e exige cuidados individualizados. Esse plano de cuidados deve visar principalmente $o$ apoio psicológico, social, a continuidade da realização de curativos e 0 retorno às atividades familiares, laborais e sociais (ROCHA JLFN, et al., 2016; VANA LPM, et al., 2020).

\section{CONSIDERAÇÕES FINAIS}

Durante análise dos artigos foi possível identificar as principais intervenções de enfermagem realizadas á vítima de queimaduras. Diante disso, evidenciou-se que o enfermeiro tem um papel fundamental desde o primeiro atendimento a essa vítima e deve ter ações efetivas que estabilize, recupere e reabilite este paciente, sempre visado a prevenção de complicações e a sua qualidade de vida. Artigos recentes destacaram a sepse como uma das principais causas de complicação e de mortalidade nesse público. Durante a fase de recuperação e reabilitação um cuidado individualizado deve ser prestado visando além das alterações físicas também as repercussões psicológicas. Destaca-se a educação em saúde, onde deve estar inclusa a rede familiar desse paciente desde sua internação até a pós-alta hospitalar. 


\section{REFERÊNCIAS}

1. AIQUOC K, et al. Avaliação da satisfação com a imagem corporal dos pacientes queimados. Revista de Enfermagem UFPE Online, 2019; 13 (4): 952-959.

2. CARVALHO RRS, et al. A dor da queimadura e suas singularidades: percepções de enfermeiras assistenciais. Revista Brasileira de Queimaduras, 2019; 18(2): 84-89.

3. COSTA ACSM, et al. Perfil funcional segundo a Classificação Internacional de Funcionalidade, Incapacidade e Saúde em pacientes queimados atendidos em hospital público. Revista Brasileira de Queimaduras, $2018 ; 17$ (1): 2-7.

4. DUTRA JPS, et al. Estudo clínico-epidemiológico de pacientes queimados internados em uma unidade de terapia intensiva em Goiás. Revista Brasileira de Queimaduras, 2017; 16 (2): 87-93.

5. FILHO FMB, et al. Análise da eficiência de uma rede de urgência para tratamento de múltiplos queimados. Revista do Colégio Brasileiro de Cirurgiões, 2019; 46 (2): e2115.

6. GUANILO MEE, et al. Avaliação da qualidade de vida relacionada à saúde no primeiro ano após a queimadura. Escola Anna Nery, 2016; 20 (1): 155-166.

7. HERIQUE DM, et al. Aprazamento seguro da terapia analgésica com opioides no paciente queimado: um estudo transversal. Revista de Enfermagem UERJ, 2017; 25: e28082.

8. LANÇONI JÚNIOR AC, et al. Comunicação entre equipe de saúde, família, criança em unidade de queimados. Psicologia em Estudo, 2017; 22 (4): 623-634.

9. LIMA VX, BRITO MEM. Percepções da equipe de enfermagem acerca da prática da educação em saúde em um centro de tratamento de queimados. Revista Brasileira de Queimaduras, 2018; 17 (1): 2-7.

10. MALTA DC, et al. Perfil dos casos de queimadura atendidos em serviços hospitalares de urgência e emergência nas capitais brasileiras em 2017. Revista Brasileira de Epidemiologia, 2020; 23 (supl.1): e200005.

11. MESCHIAL WC, et al. Intervenção educativa sobre atendimento inicial ao queimado baseada em métodos pedagógicos inovadores: percepções dos enfermeiros. Texto \& Contexto - Enfermagem, 2020; 29: e20190222.

12. MOLA R, et al. Características e complicações associadas às queimaduras de pacientes em unidade de queimados. Revista Brasileira de Queimaduras, 2018;17(1):8-13.

13. MORAES LP, et al. Apoio social e qualidade de vida na perspectiva de pessoas que sofreram queimaduras. Revista Brasileira Queimaduras, 2016; 15(3):142-147.

14. MOULIN LL, et al. Perfil sociodemográfico e clínico de vítimas de queimaduras atendidas em um hospital de referência. Revista Nursing, 2018; 21 (238): 2058-2062.

15. MOURA NR, SCHRAMM SMO. Lesões por queimaduras em idosos em um hospital de referência. Revista Brasileira de Queimaduras, 2019; 18 (2): 78-83.

16. PAN R, et al. Conhecimento de profissionais de saúde acerca do atendimento inicial intra-hospitalar ao paciente vítima de queimaduras. Revista Gaúcha Enfermagem, 2018; 39: e2017-0279.

17. PESSOA LMB, et al. Internações hospitalares de pacientes queimados em hospital de referência do estado de Alagoas. Revista Brasileira de Queimaduras, 2018; 17 (2): 1-6.

18. PINHO FM, et al. Guideline das ações no cuidado de enfermagem ao paciente adulto queimado. Revista Brasileira de Queimaduras, 2016; 15(1): 13-23.

19. RANÇÃO CSF, et al. Indicadores clínicos da sepse no paciente queimado. Revista de Enfermagem Atual In Derme, 2018; 86 (24).

20. ROCHA JLFN, et al. Qualidade de vida dos pacientes com sequelas de queimaduras atendidos no ambulatório da unidade de queimados do Hospital Regional da Asa Norte. Revista Brasileira de Queimaduras, 2016; 15(1):3-7.

21. RODRIGUES LA, et al. O profissional de saúde na Unidade de Tratamento de Queimados: Atenção e cuidado com os aspectos psicológicos dos paciente. Revista Brasileira de Queimaduras, 2019; 18 (1): 16-22.

22. SILVA JAC, et al. Epidemiologia, principais complicações e mortalidade dos pacientes atendidos em um Centro de Tratamento de Queimados na Amazônia. Revista Brasileira de Cirurgia Plástica, 2018; 33 (1): 104-109.

23. SILVEIRA RC, et al. Perfil epidemiológico dos pacientes com lesão inalatória que foram atendidos em uma Unidade de Queimados de um Hospital de Pronto-Socorro. Revista Brasileira de Queimaduras, 2017; 16(3): 150-156.

24. SOUZA MT, et al. Fluxos assistenciais de médios e grandes queimados nas regiões e redes de atenção à saúde de Minas Gerais. Cadernos Saúde Coletiva, 2018; 26 (3): 327-335.

25. VANA LPM, et al. Atualização e sistematização de sequelas em queimaduras. Cirugía Plástica Ibero-Latinoamericana, 2020; 46 (supl.1): 97-106. 